\title{
Atypical major depressive episode as initial presentation of intracranial germinoma in a male adolescent
}

This article was published in the following Dove Press journal:

Neuropsychiatric Disease and Treatment

21 December 2016

Number of times this article has been viewed

Yi-Ting Chen ${ }^{1,3,4}$

Kuan-Pin $\mathrm{Su}^{2-5}$

Jane Pei-Chen Chang ${ }^{2-5}$

'Graduate Institute of Clinical Medical

Science, China Medical University,

Taichung, Taiwan; ${ }^{2}$ Graduate Institute

of Neural and Cognitive Sciences,

China Medical University, Taichung,

Taiwan; ${ }^{3}$ School of Medicine, China

Medical University, Taichung, Taiwan;

${ }^{4}$ Department of Psychiatry, China

Medical University Hospital, Taichung,

Taiwan; ${ }^{5}$ Department of Psychological

Medicine, Institute of Psychiatry,

Psychology and Neuroscience, King's

College London, London, UK
Correspondence: Jane Pei-Chen Chang Department of Psychiatry, China Medical University Hospital, No 2 Yuh-Der Rd,

Taichung, 404, Taiwan

Tel +886975681505

Email peko80@gmail.com
Abstract: A 17-year-old adolescent boy presented with atypical major depressive episode (MDE) without specific focal neurological signs for 6 months. He had a diagnosis of intracranial germinoma, and the atypical MDE symptoms subsided after the operation. However, he had a relapse of atypical MDE 7 months after the first surgery. His mood and binge eating symptoms subsided, but intractable body weight gain only partially improved after treatment. When encountering manifestations of depression with atypical features, especially with binge eating symptoms in male children and adolescents, with early onset age, no family history, and prolonged depressive episodes, clinicians should consider not only mood disorders including bipolar spectrum disorders but also organic brain lesions such as intracranial germinoma.

Keywords: intracranial germinoma, atypical major depressive episode, binge eating behavior, body weight gain

\section{Introduction}

Primary central nervous system germ cell tumor (CNSGCT) is a relatively rare childhood malignancy that occurs at a higher incidence of $2 \%-9 \%$ in Japan and Taiwan. ${ }^{1}$ Intrasellar germinoma shows a noticeable priority for sites along the midline, ${ }^{2}$ whereas tumors arising within the sella turcica are extremely rare. ${ }^{3}$ Diabetes insipidus (DI) characterized by excessive thirst and excretion of large amounts of severely diluted urine is the most common symptom to prompt patients with intrasellar germinomas to seek medical treatment. ${ }^{4}$

There has been no report of obvious affective disorder as a first presentations of CNSGCT. Besides, issues about the mechanism of hypothalamic modulation toward the long-term outcome of disordered eating behaviors/intractable body weight (BW) gain among adolescent boys with CNSGCT was less discussed. This study reports about an adolescent boy who presented with atypical major depressive episode (MDE) as an initial characteristics of CNSGCT.

\section{Case report}

Verbal informed consent from the patient for the case report publication was acquired on the telephone due to the patient moving to another area. Institutional review board approval was not sought for this case report.

Mr A, a 17-year-old, right-handed boy, visited a psychiatric clinic due to initial presentations of depressive mood with mood reactivity, hypersomnia, poor concentration, lack of energy, binge eating, BW gain (body mass index [BMI] 
22.7-27.3 kg/m²), and impaired school performances for 6 months. Mr A's binge eating and depression developed simultaneously. He neither had a family history of psychiatric disorder, substance abuse, seizure, systemic disease, nor head injury. There were also no specific focal neurological signs during physical examinations. He had a diagnosis of MDE with atypical features with a Clinical Global Impression-Severity score of 5 and received fluoxetine $20 \mathrm{mg}$ daily as treatment.

However, despite treatment with fluoxetine, his depression symptoms persisted accompanied by intermittent headache and dizziness, but without other specific focal neurological signs. However, 6 months after the medical treatment, he developed poor left eye visual acuity and unsteady gait. Brain computed tomography (CT) and brain magnetic resonance imaging (MRI) showed intrasellar/suprasellar lobulated cystic mass and associated optic chiasm/retrochiasmatic optic tract, and a pineal gland mass (Figure 1). Abnormal laboratory data findings before operation indicated low morning and evening cortisol levels (35.75 and $5.52 \mathrm{nmol} / \mathrm{L}$, respectively) and low total T4 level (44.27 nmol/L). His headache, dizziness, and atypical MDE symptoms subsided only after receiving microsurgery and radiosurgery (Figure 2), and the histopathology report showed intrasellar, suprasellar, and pineal germinoma. After the operation, DI and hypogonadism (testosterone: $0.38 \mathrm{nmol} / \mathrm{L}$ ) were diagnosed. Hence, he received regular prednisolone
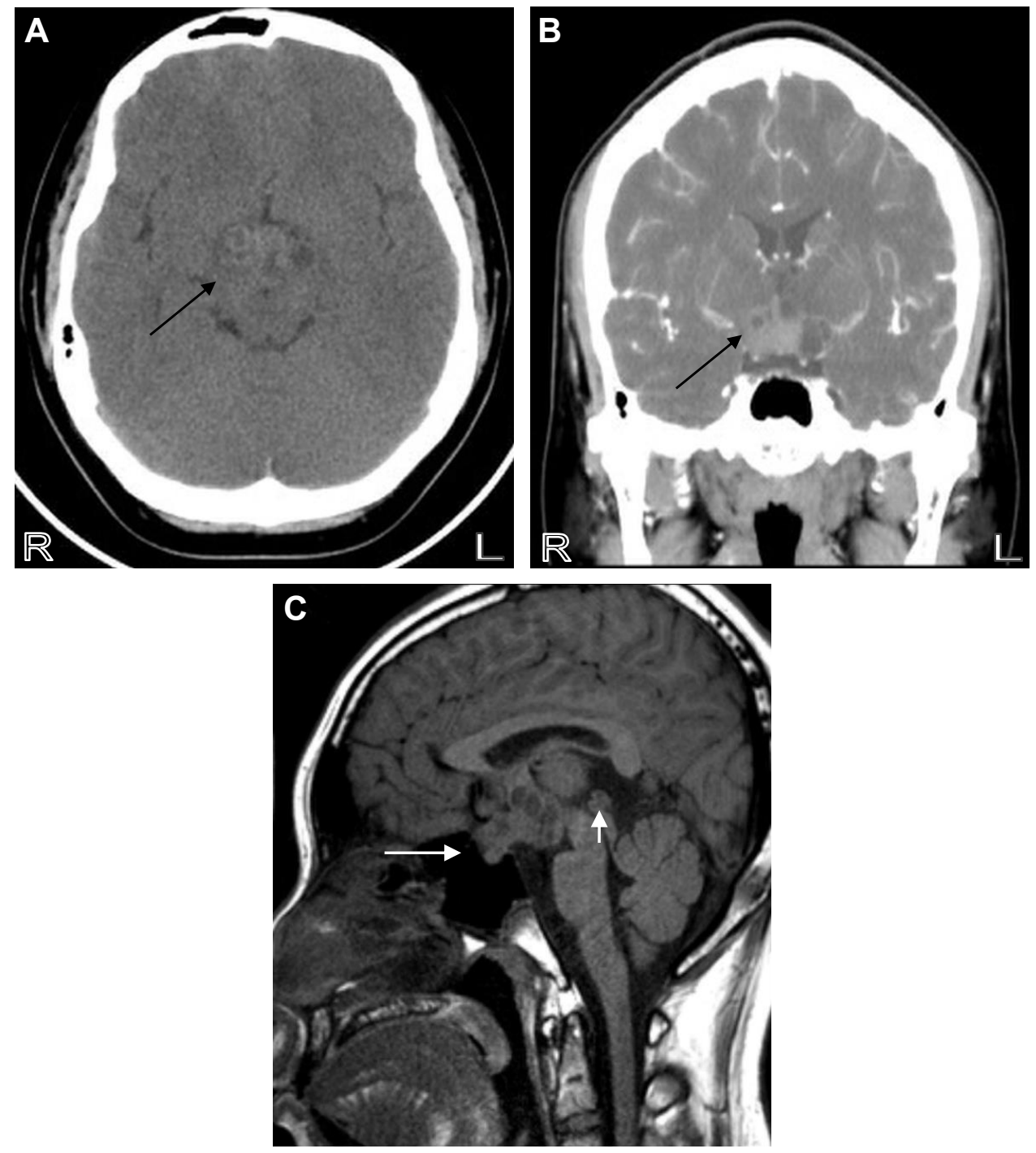

Figure I Images before the first operation.

Notes: (A and B) Brain computed tomography showed a supra/retrosellar germinoma (black arrow). (C) Brain magnetic resonance imaging T2-weighted image showed an intrasellar and suprasellar lobulated cystic germinoma with retrosellar extensions; optic chiasm and retrochiasmatic optic tract (optic chiasm indicated by white horizontal arrow) are mainly affected. No hydrocephalus. White short arrow indicates pineal germinoma. $R$ indicates right side and $L$ indicates left side. 


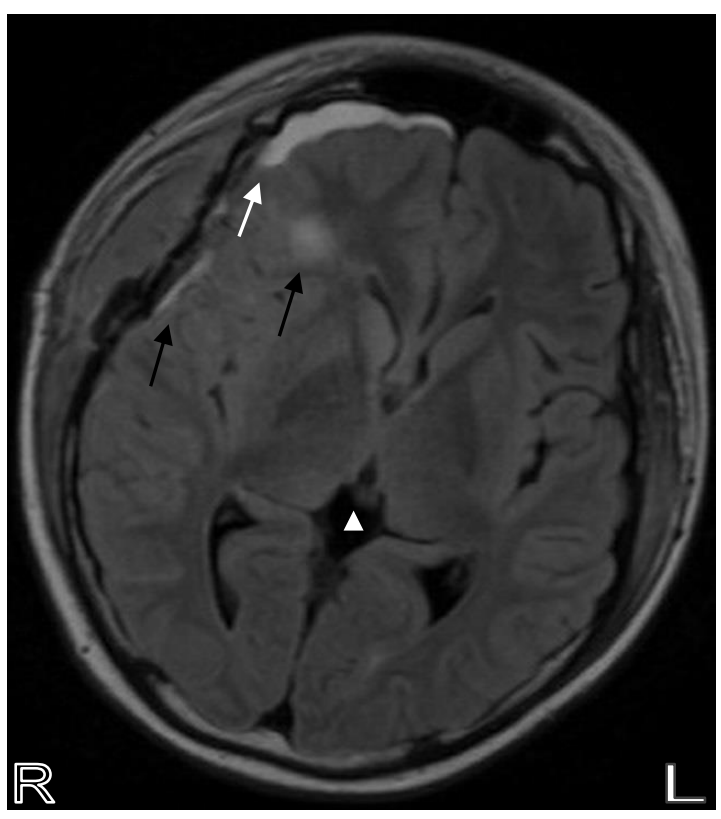

Figure 2 Follow-up magnetic resonance imaging after the first operation. Notes: Some parenchymal hemorrhage (black arrows) and edema were seen over the right frontal lobe along the surgical route. A subacute subdural hematoma (white arrow) was seen over the right frontal region. White arrowhead indicates a small pineal germinoma.

$10 \mathrm{mg} /$ day, thyroxine $200 \mu \mathrm{g} / \mathrm{day}$, desmopressin $0.3 \mathrm{mg} /$ day, and testosterone $200 \mathrm{mg}$ injection every month for hypopituitarism.

Approximately 7 months after the first surgery, he had another recurrent episode of atypical MDE, with exacerbation of depressive mood, anhedonia, increased appetite and hunger, increased psychomotor agitation, hypersomnia, and total BW gain of $5.7 \mathrm{~kg}$. Brain MRI showed local recurrence of residual tumor at optic chiasm and hypothalamus and obstructive hydrocephalus (Figure 3). The patient's depressive mood, increased appetite, and hunger partially improved after receiving ventriculoperitoneal shunting, radiosurgery, and diet restriction (Figure 4). One year after the second surgery, his BMI increased to $35.2 \mathrm{~kg} / \mathrm{m}^{2}$ despite an improvement in hyperphagia. Approximately 3 years after the second surgery, with the correction of his medical condition and nutrition, his BMI partially reversed to $28.1 \mathrm{~kg} / \mathrm{m}^{2}$.

\section{Discussion}

The patient met the definition of atypical MDE according to The Diagnostic and Statistical Manual of Mental Disorders, Fourth Edition, Text Revision (DSM-IV-TR), with symptoms such as mood reactivity, binge eating, significant BW gain, and hypersomnia. Moreover, the physician justified the patient's dizziness without specific neurological signs or classical triads of intracranial germinoma (DI, panhypopituitarism, and visual disturbances) ${ }^{6}$ at the beginning of the treatment course as the common side effect of fluoxetine. ${ }^{7}$ It may mask the unspecific symptoms of intracranial germinoma with the dizziness/headache and delay the timing for accurate diagnosis and proper treatment. Furthermore, $\sim 45 \%-95 \%$ of patients with depression reported only somatic symptoms. ${ }^{8}$ Therefore, the physician may initially diagnose the physical complaints and atypical presentations of depression in this patient without other specific neurological deficits as MDE with atypical features, and it may deflect the attention of a progressing intracranial tumor to the visual acuity loss that appeared 6 months after antidepressant treatment.

The patient's atypical MDE is similar to the presentation of hypothalamic syndrome, and one of the most common etiologies of hypothalamic syndrome in children is CNSGCT. ${ }^{9}$ Hypothalamic syndrome is often characterized by features of hypopituitarism, ${ }^{10}$ depression, ${ }^{9}$ polyphagia, and obesity. ${ }^{9}$ Thus, the patient's 1) hypothyroidism (characterized by depression and weight gain), ${ }^{11,12}$ 2) hypoadrenalism (shown as depression), ${ }^{13}$ and 3) hypogonadism (presented with mood swings and weight gain $)^{14}$ may be secondary to hypopituitarism and overlap with the presentations of the atypical MDE.

The patient's mood partially improved after treatment; nevertheless, the causality between the organic lesion and depression could still not be established, that is, whether the removal of germinoma, normalizing the intracranial pressure by ventriculoperitoneal shunting, or decrement of other confounders led to the remission of depression was not certain. Moreover, although there were indices for biological causes, a dual diagnosis with functional depression should also be considered.

The patient had right frontal parenchymal hemorrhage and edema after the first operation. His psychomotor agitation also exacerbated at the same time. Although depression has been associated with the left hemisphere in some studies, ${ }^{15}$ the findings have been inconsistent. Pathological laughing, euphoric mood alteration, ${ }^{16}$ and inappropriate cheerfulness ${ }^{17}$ have been related to right-hemisphere injury and right hemispherectomy. Moreover, one systemic review did not support the association between the subsequent depression and leftside stroke. ${ }^{18}$ In short, brain insult in either hemisphere may be associated with depression.

Another interesting symptom is the disordered eating behavior in this patient, which rarely occurs in boys. ${ }^{19} \mathrm{Mr} \mathrm{A}$ pointed out that, "I didn't feel disgusted with myself or guilt 

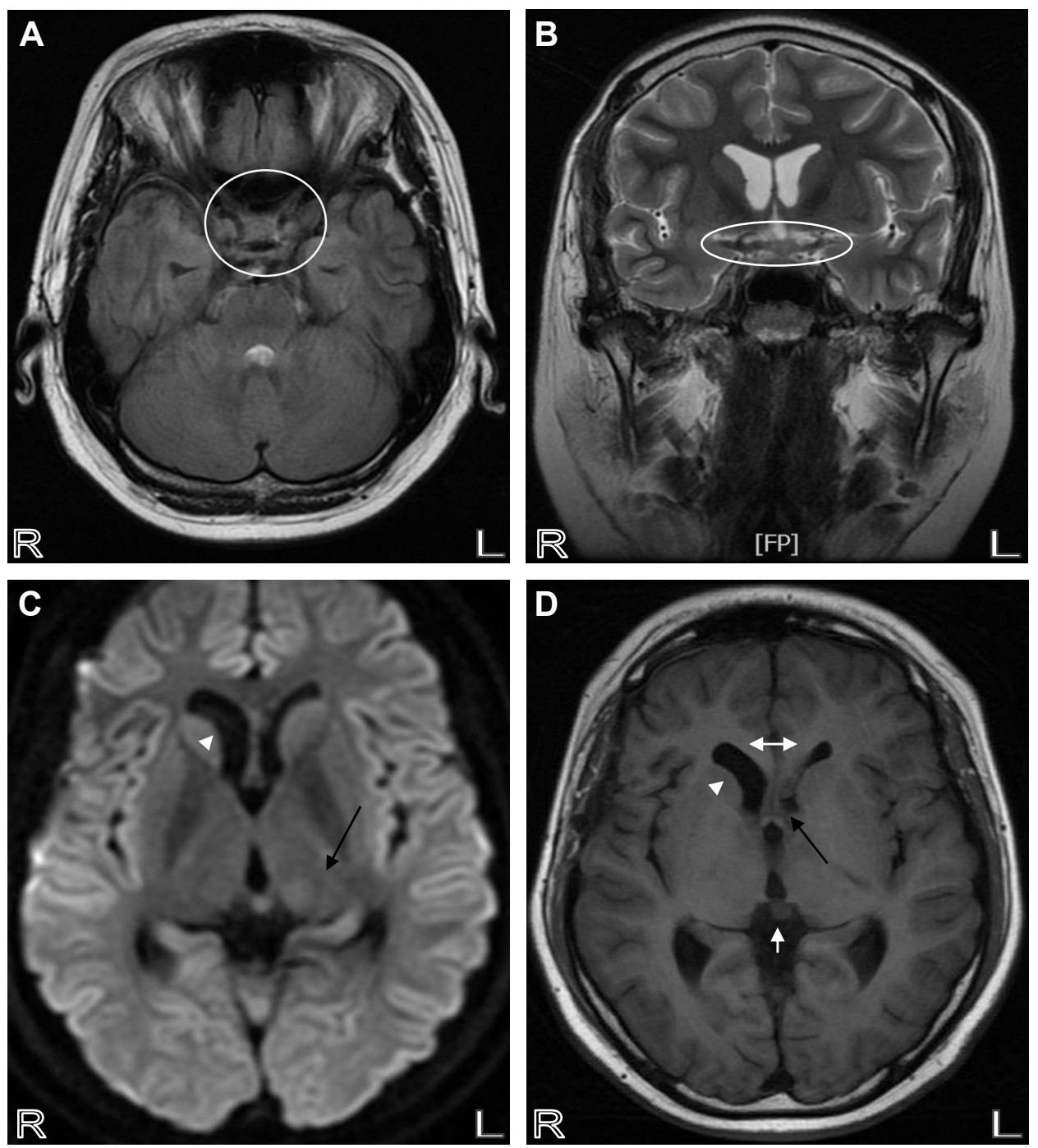

Figure 3 Follow-up images $\sim 7$ months after the first operation.

Notes: (A) Axial view of T2-FLAIR image of MRI. (B) Coronal view of T2-FrFSE image of MRI. (C) Diffusion-weighted imaging of MRI. (A-C) Indicate the recurrence/ regrowth of residual germinoma involving optic chiasm (A, B: circle), hypothalamus (C: black arrow). Mild dilated ventricles were noted (C: white arrowhead). (D) TI weighted image of MRI: the intra/suprasellar germinoma was more superiorly extended involving foramen of Monro (black arrow) and nearby genu of corpus callosum (double-headed arrow). No significant interval change of pineal gland germinoma (white arrow) compared to (C). Mild hydrocephalus (white arrowhead).

Abbreviations: MRI, magnetic resonance imaging; T2-FLAIR, T2-weighted fluid-attenuated inversion recovery; T2-FrFSE, T2-weighted fast recovery fast spin echo.

after consuming a large amount of meals," which is an uncommon feature of the typical eating disorder. Mr A totally recovered from the binge eating behavior after the surgery, but his BW gain was only partially reversed. Pathological hyperphagia and obesity have been related to lesions involving arcuate nucleus, ventrolateral nucleus, ventromedial nucleus, and paraventricular nucleus in the hypothalamus. ${ }^{20}$ In addition, suprasellar germinoma causing damage to the hypothalamuspituitary axis frequently relates to the hyperlipidemia and may play a part in the development of obesity. ${ }^{21}$ In contrast, continuous BW gain after resection of hypothalamus germinoma might be associated with the decline in sympathetic nerve activity which reduces the metabolic rate. ${ }^{22}$
After the first operation, the patient developed subacute subdural hematoma and edema over the right frontal region; this area has been associated with disordered eating behavior. ${ }^{23}$ The lesions of the right anterior brain have also been associated with continuous thinking about food and preference for fine eating. ${ }^{24}$ Based on the previous research studies, it is conjectured that damage to the right inferior frontal cortex, proposed to be responsible for the inhibiting response, ${ }^{25}$ may be correlated to the polyphagia and weight gain. Furthermore, medication-associated BW gain should also be considered in this patient, as reports have implied that the long-term treatment of corticosteroids, thyroxine, or testosterone may result in an increase in BW..$^{26-28}$ 


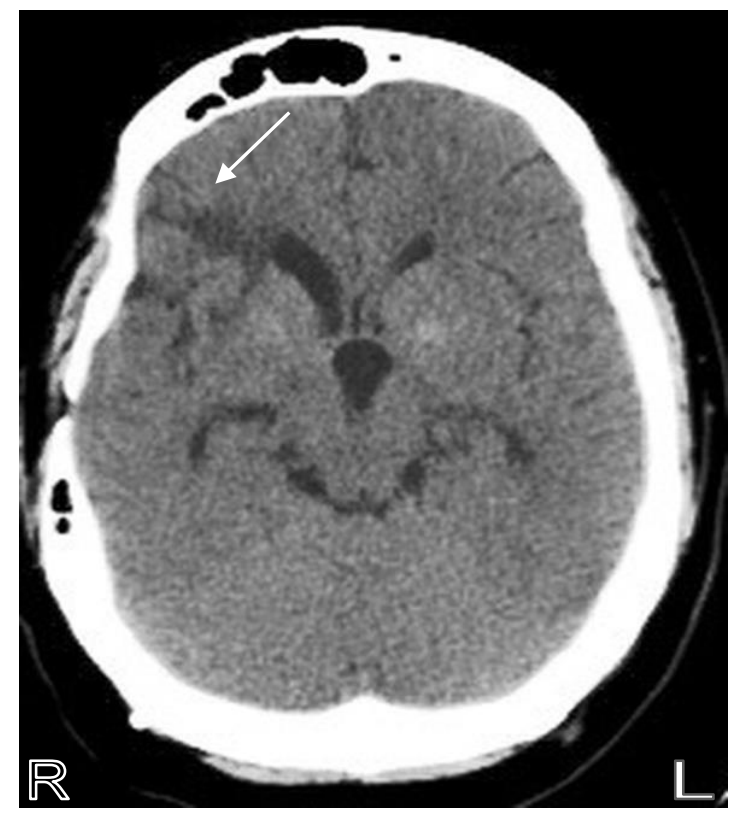

Figure 4 Follow-up brain computed tomography after the second operation. Notes: Focal brain tissue damage in the right frontal lobe (white arrow). $R$ indicates right side and $\mathrm{L}$ indicates left side.

\section{Conclusion}

When encountering manifestations of depression with atypical features, especially with binge eating symptoms in male children and adolescents, with an early onset age, no family history, and prolonged depressive episodes, clinicians should consider not only mood disorders including bipolar spectrum disorders but also organic brain lesions such as intracranial germinoma for differential diagnosis. On the contrary, even with brain lesions, a dual diagnosis with functional depression should also be considered.

\section{Acknowledgment}

The authors thank Dr Yi-Chia Ku for providing expertise on the brain image findings.

\section{Disclosure}

The authors report no conflicts of interest in this work.

\section{References}

1. Crawford JR, Santi MR, Vezina G, et al. CNS germ cell tumor (CNSGCT) of Childhood: presentation and delayed diagnosis. Neurology. 2007; 68:1668-1673.

2. Frank G, Galassi E, Fabrizi AP, Frank F, Manetto V. Primary intrasellar germinoma: case report. Neurosurgery. 1992;30:786-788.

3. Ballesteros MD, Durán A, Arrazola J, et al. Primary intrasellar germinoma with synchronous pineal tumor. Neuroradiology. 1997;39(12): 860-862.

4. Marcovitz S, Guyda HJ, Finlayson MH, Wee R, Hardy J. Intrasellar germinoma associated with hyperprolactinemia. Surg Neurol. 1984;22: $387-396$.
5. American Psychiatric Association. Diagnostic and Statistical Manual of Mental Disorders. Fourth Edition, Text Revision. Washington (DC): American Psychiatric Association; 2000:420-422.

6. Depujari CE, Kumar A, Karmarkar VS, Biyani NK, Mhatre M, Shah NJ. Pediatric suprasellar lesions. J Pediatr Neurosci. 2011;6(Suppl 1): S46-S55.

7. Cascade E, Kalali AH, Kennedy SH. Real-world data on SSRI antidepressant side effects. Psychiatry (Edgmont). 2009;6(2):16-18.

8. Simon GE, VonKorff M, Piccinelli M, Fullerton C, Ormel J. An international study of the relation between somatic symptoms and depression. N Engl J Med. 1999;341:1329-1335.

9. Liu M, Du J, Sang Y, Wu Y, Yan J, Zhu C. Clinical analysis on 33 patients with hypothalamic syndrome in Chinese children. J Pediatr Endocrinol Metab. 2014;27(3-4):291-297.

10. Horowitz MB, Hall WA. Central nervous system germinomas. A review. Arch Neurol. 1991;48(6):652-657.

11. Gold MS, Pottash AL, Extein I. Hypothyroidism and depression. Evidence from complete thyroid function evaluation. JAMA. 1981; 245(19):1919-1922.

12. Djrolo F, Houngbé F, Attolou V, Hountondji B, Quenum K, Hountondji A. Hypothyroidism: clinical and etiological aspects in Cotonou (Republic of Benin). Sante. 2001;11(4):245-249.

13. Thomsen AF, Kvist TK, Andersen PK, Kessing LV. The risk of affective disorders among patients with adrenocortical insufficiency: secondary publication. Ugeskr Laeger. 2007;169(16):1473-1475.

14. Abadilla KA, Dobs AS. Topical testosterone supplementation for the treatment of male hypogonadism. Drugs. 2012;72(12):1591-1603.

15. Narushima K, Kosier JT, Robinson RG. A reappraisal of poststroke depression, intra- and inter-hemispheric lesion location using metaanalysis. J Neuropsychiatry Clin Neurosci. 2003;15(4):422-430.

16. Sackeim HA, Greenberg MS, Weiman AL, Gur RC, Hungerbuhler JP, Geschwind N. Hemispheric asymmetry in the expression of positive and negative emotions. Neurologic evidence. Arch Neurol. 1982;39(4): $210-218$.

17. Starkstein SE, Robinson RG, Honig MA, Parikh RM, Joselyn J, Price TR. Mood changes after right-hemisphere lesions. Br J Psychiatry. 1989;155:79-85.

18. Carson AJ, MacHale S, Allen K, et al. Depression after stroke and lesion location: a systematic review. Lancet. 2000;356(9224):122-126.

19. Hoek HW, van Hoeken D. Review of the prevalence and incidence of eating disorders. Int J Eat Disord. 2003;34:383-396.

20. Haliloglu B, Bereket A. Hypothalamic obesity in children: pathophysiology to clinical management. J Pediatr Endocrinol Metab. 2015;28: 503-513.

21. Adachi M, Tsuchiya T, Muroya K, Asakura Y, Sekido K, Sato H. Prevalence of obesity, hyperlipemia and insulin resistance in children with suprasellar brain tumors. Clin Pediatr Endocrinol. 2007;16(1): $1-9$.

22. Watanabe T, Iwase S, Saito K, Nagatani T, Yoshida J. Altered sympathetic thermoregulation in patients with hypothalamic dysfunction following resection of suprasellar tumor. Auton Neurosci. 2004;112: $80-87$.

23. Uher R, Treasure J. Brain lesions and eating disorders. J Neurol Neurosurg Psychiatry. 2005;76(6):852-857.

24. Regard M, Landis T. "Gourmand syndrome": eating passion associated with right anterior lesions. Neurology. 1997;48(5):1185-1190.

25. Aron AR, Robbins TW, Poldrack RA. Inhibition and the right inferior frontal cortex: one decade on. Trends Cogn Sci. 2014;18(4):177-185.

26. Aljebab F, Choonara I, Conroy S. Long-course oral corticosteroid toxicity in children. Arch Dis Child. 2016;101(9):e2.

27. Kelderman-Bolk N, Visser TJ, Tijssen JP, Berghout A. Quality of life in patients with primary hypothyroidism related to BMI. Eur J Endocrinol. 2015;173(4):507-515.

28. Bhasin S, Storer TW, Berman N, et al. Testosterone replacement increases fat-free mass and muscle size in hypogonadal men. $J$ Clin Endocrinol Metab. 1997;82(2):407-413. 


\section{Publish your work in this journal}

Neuropsychiatric Disease and Treatment is an international, peerreviewed journal of clinical therapeutics and pharmacology focusing on concise rapid reporting of clinical or pre-clinical studies on a range of neuropsychiatric and neurological disorders. This journal is indexed on PubMed Central, the 'PsycINFO' database and CAS,

and is the official journal of The International Neuropsychiatric Association (INA). The manuscript management system is completely online and includes a very quick and fair peer-review system, which is all easy to use. Visit http://www.dovepress.com/testimonials.php to read real quotes from published authors.

Submit your manuscript here: http://www.dovepress.com/neuropsychiatric-disease-and-treatment-journal 